\title{
Are urodynamics still useful?
}

\section{Stephen S. Steele, MD, FRCSC}

Departments of Urology and Pediatrics, Queen's University, Kingston, ON

See related article on page 185 .

Cite as: Can Urol Assoc J 2013;7(5-6):e452-3. http://dx.doi.org/10.5489/cuaj.1398 Published online June 12, 2013.

A sk a room full of urologists about the usefulness of urodynamics (UDS) and you are likely to get a plethora of opinions. But is this a question we need to ask? I would suggest that it is, and we need to explore the accumulating data to answer that question. Richard and colleagues suggest that there may be issues with using a pressure flow study (PFS) to diagnose bladder outlet obstruction (BOO) in women. ${ }^{1}$ They clearly demonstrate that a 6 French catheter used during a PFS can be obstructive and over-diagnose BOO in over $11 \%$ of women. They found that urodynamics for identifying $\mathrm{BOO}$ was inferior and actually falsely elevated the number of women with BOO. ${ }^{1}$

This situation is not isolated to the over-diagnosis of BOO by obstructing catheters. Many other lower urinary tract problems are also difficult to demonstrate reliably and consistently on urodynamics. Detrusor overactivity (DO) is particularly troublesome, and cystometry often fails to diagnose DO despite severe symptoms of overactive bladder. ${ }^{2}$ In fact, the reproducibility of finding DO can vary on the same patient whether the studies are performed consecutively or on different days., ${ }^{3,4}$ addition, many urologists perform UDS on women with stress urinary incontinence (SUI), yet the data suggest that over $50 \%$ of women with SUI will not leak during urodynamics with the urethral catheter in place. $^{5,6}$

So why do we perform urodynamics? Does it change how we treat our patients? Does it change our results? The answers might surprise you. A recent study published in Neurourology and Urodynamics suggests that for women undergoing UDS for predominantly SUI, the UDS increased physicians' confidence in their clinical diagnosis, but it did not correlate with treatment success. ${ }^{7}$ In fact, even in cases where UDS significantly changed clinical diagnosis it infre- quently changed the treatment plan or the surgeons' decision to cancel, change or modify surgical plans. ${ }^{8}$

Some of the issues may revolve around the test itself. There is widespread variability in the technique and interpretation of urodynamics. ${ }^{2}$ This is not surprising, since we are attempting to recreate a real-life situation in a laboratory setting where the resulting imagery more closely resembles something out of an old Frankenstein movie. Think I am over exaggerating? Go into a UDS suite and watch the poor patient standing naked in the middle of the room with a catheter in their rectum and bladder coughing, while a nurse tries to quantify the amount of urinary leakage. Is it any wonder that there is such variability in UDS tracings?

However, even with the widespread variability in tracings and interpretations, UDS can still be a useful entity if incorporated properly into the patient assessment. UDS need to be interpreted in the context of the global assessment of the patient, including examination, diaries and residual urine as well as other pertinent information. ${ }^{2}$ Using all the resources at our disposal to diagnose and treat our patients has always been the best treatment algorithm. The danger lies in allowing one particular test, with no established standards in either its administration or its interpretation, to unduly influence our patient care. Once that occurs, the test has truly outlived its usefulness.

Competing interests: None declared.

\section{References}

1. Richard P, Ordonez NI Tu LM. The effect of a 6 Fr catheter in women: Are they obstructive? Can Urol Assoc J 2013;7:185-8. http://dx.doi.org/10.5489/cuaj.1320

2. Gormley EA, Lightmer DJ, Burgio, et al. Diagnosis and treatment of overactive bladder (non-neurogenic) in adults: AUA/SUFU guideline. J Urol 2012;188(6 Suppl):2455-63. http://dx.doi.org/10.1016/i.juro.2012.09.079

3. Ockrim J, Laniado ME, Khoubehi B, et al. Variability of detrusor overactivity on repeated filling cystometry in men with urge symptoms: comparison with spinal cord injury patients. BJU Int 2005;95:587. http://dx.doi.org/10.1111/i.1464-410X.2005.05344.x

4. Homma Y, Kondo Y, Takahashi $S$, et al. Reproducibility of cystometry in overactive detrusor. Eur Urol 2000;38:681. http://dx.doi.org/10.1159/000020362 
The usefulness of urodynamics

5. Maniam $P$, Goldman HB. Removal of transurethral catheter during urodynamics may unmask stress urinary incontinence. J Urol 2002;167:2080. http://dx.doi.org/10.1016/S0022-5347(05)65089-6

6. Huckabay C, Twiss C, Berger A, et al. A urodynamics protocol to optimally assess men with postprostatectomy incontinence. Neurourol Urodyn 2005;24:622. http://dx.doi.org/10.1002/nau.20182

7. Zimmern P, Litman H, Nager C, et al. Pre-Operative Urodynamics in Women with Stress Urinary Incontinence Increases Physician Confidence, But Does Not Improve Outcomes. Neurourol Urodyn 2013;Epub 2013 Apr 1. htrp://dx.doi.org/10.1002/nau.22398.
8. Sirls LI, Richter HE, Litman HJ, et al. The effect of urodynamic testing on clinical diagnosis, treatment plan and outcomes in women undergoing stress urinary incontinence surgery. J Urol 2013;189:204-9. http://dx.doi.org/10.1016/i.juro.2012.09.050

Correspondence: Dr. Stephen S. Steele, 76 Stuart St, Kingston, 0N K7L 2V7; steeles@kgh.kari.net 